Journal of Physical Science, Vol. 28(2), 19-29, 2017

\title{
Estimation of Precipitable Water Vapour in Nigeria Using NIGNET GNSS/GPS, NCEP-DOE Reanalysis II and Surface Meteorological Data
}

\author{
Oladiran J. Abimbola, ${ }^{1 *}$ Oluwasesan A. Falaiye ${ }^{2}$ and Joseph Omojola ${ }^{1}$ \\ ${ }^{1}$ Department of Physics, Federal University Lafia, PMB 146, \\ Lafia 950101, Nasarawa State, Nigeria \\ ${ }^{2}$ Department of Physics, University of Ilorin, PMB 1515, \\ Ilorin 240003, Kwara State, Nigeria
}

${ }^{*}$ Corresponding author: ladiran@gmail.com

Published online: 15 August 2017

To cite this article: Abimbola, O. J., Falaiye, O. A. \& Omojola, J. (2017). Estimation of precipitable water vapour in Nigeria using NIGNET GNSS/GPS, NCEPDOE reanalysis II and surface meteorological data. J. Phys. Sci., 28(2), 19-29, https://doi.org/10.21315/jps2017.28.2.2

To link to this article: https://doi.org/10.21315/jps2017.28.2.2

\begin{abstract}
In this paper, data from Nigerian Global Positioning System/Global Navigation Satellite System (GPS/GNSS) network (NIGNET) for the year 2012, together with those from surface meteorological stations, National Center for Environmental Prediction (NCEP) Reanalysis II, and the Department of Energy (DOE) Numerical Weather Prediction (NWP) model have been used to estimate the precipitable water vapour (PWV) in three NIGNET stations across Nigeria (i.e., Zaria, Abuja and Lagos). The GPS/ GNSS data was analysed using RTKLIB (ver. 2.4.2) open source GPS/GNSS software. This work aims to highlight the importance of GPS PWV in NWP modelling as well as to show that GPS PWV data could be assimilated into NWP models leading to improved weather forecast. The measured PWV by GPS/GNSS was found and compared with NCEP Reanalysis II, with $R^{2}$ of 0.08, 0.006 and 0.106, RMS error of $0.32 \mathrm{~cm}, 0.29 \mathrm{~cm}$ and $0.99 \mathrm{~cm}$, while the surface meteorological data was also compared, with $R^{2}$ of 0.114 , 0.045 and 0.004, RMS error of $0.34 \mathrm{~cm}, 0.30 \mathrm{~cm}$ and $0.28 \mathrm{~cm}$ for Zaria, Abuja and Lagos respectively.
\end{abstract}

Keywords: Precipitable water vapour, GPS/GNSS, Nigeria, Butler's equation, RTKLIB

(C) Penerbit Universiti Sains Malaysia, 2017. This work is licensed under the terms of the Creative Commons Attribution (CC BY) (http://creativecommons.org/licenses/by/4.0/). 


\section{INTRODUCTION}

Water vapour, a small component of the atmosphere, plays a very significant role in the atmospheric dynamics. It is also hugely responsible for the existence of the biosphere. Among the various measures of atmospheric water vapour, precipitable water vapour (PWV) is very important as it accurately measures the quantity of the atmospheric water vapour in contrast to measuring percentage or ratio of the water vapour. Among the uses of the PWV are in the numerical weather prediction (NWP) models, pattern analysis and rain forecast, as well as determination of climate change trend. ${ }^{1-3}$

The mass of water vapour, $m_{v}$, in an atmospheric column with cross-sectional area $\mathrm{A}$ is represented with the following equation:

$m_{v}=A m_{w} \int_{o}^{z} n_{w}(z) d z$

where $m_{v}$ is the mass of water molecules (18amu) and $n_{v}$ is the number density of water molecules. The integration is done from the surface to the altitude $\mathrm{z}$, and using the conservation of mass principle, the ideal gas equation as shown by Butler is: ${ }^{4}$

$P W V=\frac{m_{w} P_{o} H}{\rho l k T_{o}}$

where $P_{o}$ is the surface water vapour partial pressure, $T_{o}$ is the surface ambient temperature, $\rho_{l}$ is the liquid water density $\left(1000 \mathrm{~kg} / \mathrm{m}^{3}\right), k$ is the Boltzmann constant $\left(1.38 \times 10^{-23} \mathrm{~J} / \mathrm{K}\right)$ and $H$ is the scale height (assumed to be $\left.15 \mathrm{~km}\right)$. Substituting all the constants, Equation 2 reduces to:

$P W V \approx \frac{P_{o}}{3 T_{o}}$

The use of global positioning system (GPS) to remotely sense the atmospheric water vapour was developed by Bevis et al. and the superiority of this method of estimating PWV was demonstrated by Businger et al. ${ }^{3,5}$ Following these pioneering works, several researchers have measured PWV using Nigerian Global Positioning System/Global Navigation Satellite System (GPS/GNSS) data and the results have been found to compare very well with other methods of estimating PWV. For instance, Coster et al. used a 6-station GPS antenna network in Europe to measure PWV and found an agreement of between 1 and $2 \mathrm{~mm}$ with the radiosonde and microwave water vapour. ${ }^{6}$ Behren et al. and Kwon et al. compared PWV measured with GPS and NWP models and found good agreement. ${ }^{7,8}$ 
Using appropriate software, the zenith total delay (ZTD), which occurs due to attenuation of the GPS/GNSS signal by the troposphere, could be estimated. The ZTD is composed of the attenuation due to the dry component of the troposphere (known as the zenith hydrostatic delay [ZHD]) and the delay due to the water vapour in the troposphere (known as the zenith wet delay [ZWD]):

$\mathrm{ZTD}=\mathrm{ZWD}+\mathrm{ZHD}$

From the surface pressure, latitude and the GPS/GNSS antenna height, the ZHD could be estimated using the Saastamoinen model and hence ZWD could be obtained. ${ }^{8}$ The PWV is directly related to the ZWD as following:

$\mathrm{PWV}=\Pi \times \mathrm{ZWD}$

where $\Pi$ is a dimensionless constant given by:

$$
\prod=\frac{10^{6}}{\rho R_{v}\left(\frac{k_{3}}{T_{m}}+k_{2}^{\prime}\right)}
$$

where $\rho$ is the density of liquid water $\left(999.9 \mathrm{~kg} / \mathrm{m}^{3}\right), R_{v}$ is the specific gas constant of water vapour $(461.5 \mathrm{~J} / \mathrm{kg} . \mathrm{K}), k_{2}^{\prime}(22.1 \mathrm{~K} / \mathrm{hPa})$ and $k_{3}\left(370100 \mathrm{~K}^{2} / \mathrm{hPa}\right)$ are from widely used formula for atmospheric refractivity and could be found in Bevis et al. ${ }^{10} T_{m}$ is the atmospheric mean temperature which is empirically related to the surface temperature $T_{s}$ (in Kelvin), as found by Bevis et al. ${ }^{10}$ by:

$T_{m}=70.2+0.72 T_{s}$

In this work, we attempted using the network of GPS/GNSS antenna, setup by the Nigerian government for GIS purpose to: estimate precipitable water vapour, the results of which will be compared with that of the numerical weather prediction model (NCEP Reanalysis II) and Butler's equation that uses surface data; highlight the importance of GPS PWV in numerical weather modelling; and show that GPS PWV compares well with NWP PWV, hence showing that other meteorological variables GPS PWV can as well be assimilated into NWP models in order to improve weather forecasting, particularly precipitation forecast. 


\section{EXPERIMENTAL}

The GNSS data for Zaria (ABUZ), Abuja (OSGF) and Lagos (ULAG) were obtained from the Nigerian GNSS Reference Network (NIGNET) (Figure 1). The NIGNET was established by the Office of the Surveyor General of the Federation (OSGoF) in collaboration with SEGAL and University of Beira Interior and Institute Geophysical Infante D. Luíz, Portugal. ${ }^{11}$ The International Terrestrial Reference Frame, solution 2005 (ITRF2005), and the GPS coordinates of the ABUZ, OSGF and ULAG stations are shown in Table 1. Each NIGNET station is equipped with Trimble CORS, and NetR8 receivers with choke-ring antenna, type TRM59800.00. Each of the station has a USB modem and a router to enable them to communicate data to the control centre, where the data is eventually made available for public download at NIGNET website (www.nignet.net).

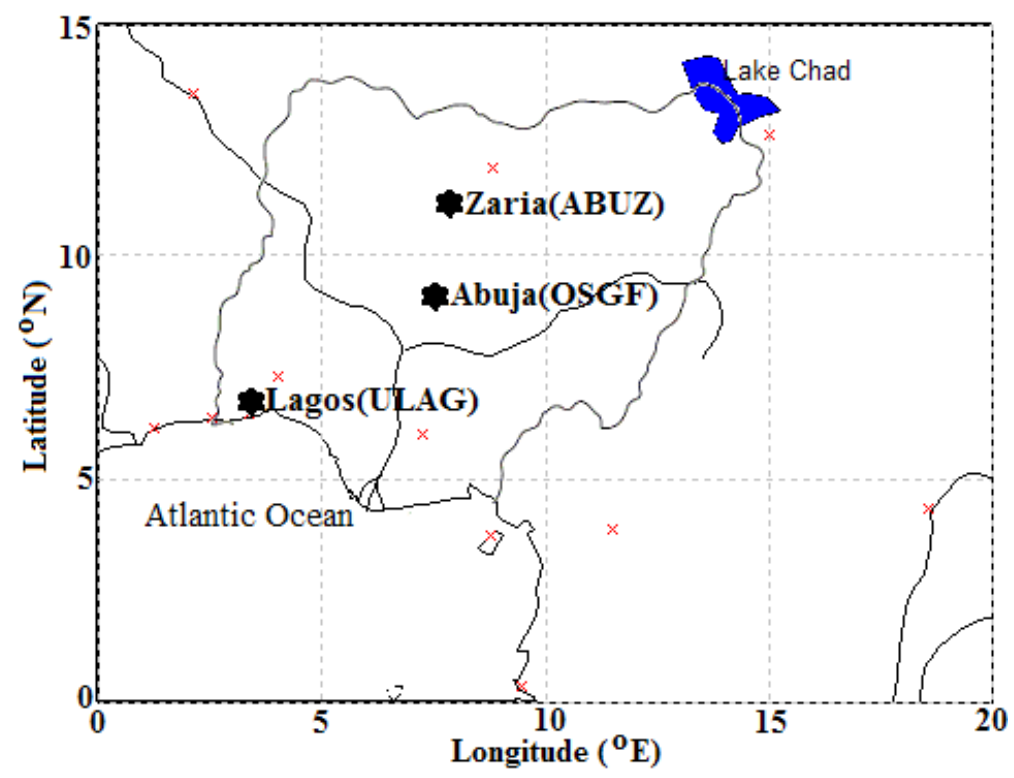

Figure 1: The Nigerian NIGNET stations used in this work.

Table 1: The GPS coordinates and the NCEP Reanalysis II coordinates used for this study.

\begin{tabular}{lllll}
\hline & \multicolumn{2}{l}{$\begin{array}{l}\text { NCEP/DOE Reanalysis II } \\
\text { coordinates }\end{array}$} & \multicolumn{2}{c}{ GPS coordinates } \\
\cline { 2 - 5 } & Lat. $\left({ }^{\circ} \mathrm{N}\right)$ & Lon. $\left({ }^{\circ} \mathrm{E}\right)$ & Lat. $\left({ }^{\circ} \mathrm{N}\right)$ & Lon. $\left({ }^{\circ} \mathrm{E}\right)$ \\
\hline ABUZ (Zaria) & 12.5 & 07.5 & 11.2 & 07.7 \\
OSGF (Abuja) & 10.0 & 07.5 & 09.0 & 07.5 \\
ULAG (Lagos) & 07.5 & 02.5 & 06.5 & 03.4 \\
\hline
\end{tabular}


Real Time Kinematic Library (RTKLIB), a GNSS software, was used to analyse the GNSS/GPS data to obtain the ZTD, from which the precipitable water vapour was then estimated. The RTKLIB (ver. 2.4.2) is an open source software for standard and precise positioning with GNSS/GPS.

The numerical weather prediction model of the National Center for Environmental Predictions (NCEP) and the Department of Energy (DOE), called Reanalysis II, assimilates meteorological parameters from a variety of sources. ${ }^{12}$ The spatial resolution of the NCEP-DOE Reanalysis II data is at the T62 Gaussian Grid with a resolution of $2.5^{\circ}$ by $2.5^{\circ}$. NCEP-DOE Reanalysis II uses the Rapid Radiative Transfer Model (RRTM) developed by the Atmospheric and Environmental Research (AER) group. ${ }^{13}$ The precipitable water vapour data from the NCEP-DOE Reanalysis II obtained in netCDF file format was extracted using Panoply (Version 4.3.1, Build F9V1) open-source software. MATLAB ${ }^{\circledR}$ was used for calculations, data plotting and regression analysis. The surface meteorological data was obtained from www.weatherspark.com. The website has surface data archive from national meteorological stations across the globe.

\section{RESULTS AND DISCUSSION}

The result of the precipitable water vapour as measured from the NIGNET GNSS/ GPS data is shown in Figure 2 for Zaria, Abuja and Lagos respectively. The maximum PWV for the three stations were found to be $48.8 \mathrm{~mm}, 51.4 \mathrm{~mm}$ and $52.5 \mathrm{~mm}$, for the three areas respectively. From these maxima values, the gradual increase in moisture from the station closer to the desert (Zaria) to the station at the coast (Lagos) could be observed.

The measured PWV from the NIGNET GNSS/GPS data was compared with the NWP model of NCEP Reanalysis 2 and the measured values using the Butler's equation (Equation 3). The results are shown in Figures 3, 4 and 5, for Zaria, Abuja and Lagos respectively. The coefficient of determination $\mathrm{R}^{2}$ between the GPS/ GNSS results and the Reanalysis II for each of the areas were found to be 0.08 , 0.006 and 0.105 respectively, while the RMS errors were found to be $0.32 \mathrm{~cm}$, $0.29 \mathrm{~cm}$ and $0.99 \mathrm{~cm}$. Prasad and Singh did similar comparison for three stations in India and found $\mathrm{R}^{2}$ of $0.87,0.77$ and 0.60 while RMS error was found to be $0.839 \mathrm{~cm}, 0.697 \mathrm{~cm}$ and $0.930 \mathrm{~cm} .{ }^{14}$ 


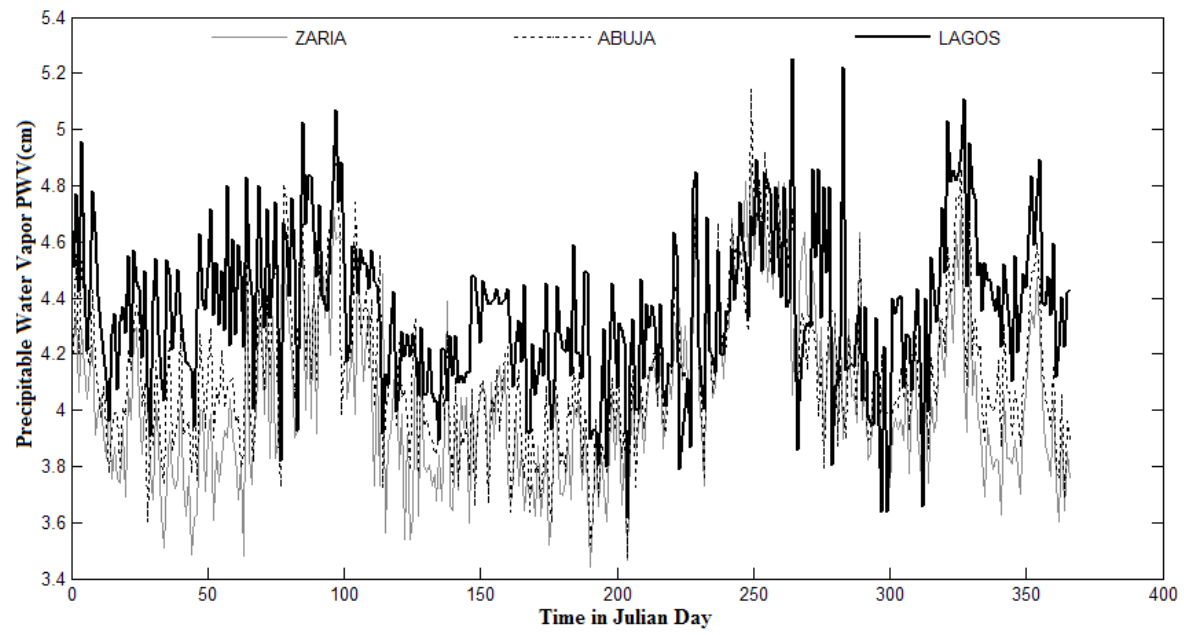

Figure 2: Daily average of PWV for Lagos, Abuja and Zaria, for year 2012, using the NIGNET GNSS/GPS data.

The correlational result between the GPS/GNSS results and those from the Butler's equation yielded $\mathrm{R}^{2}$ of $0.114,0.045$ and 0.004 for Zaria, Abuja and Lagos respectively while the RMS errors were found to be $0.34 \mathrm{~cm}, 0.30 \mathrm{~cm}$ and 0.28 $\mathrm{cm}$. The comparison between the Reanalysis II results and the Butler's equation results were also attempted and it was found that the $\mathrm{R}^{2}$ are $0.761,0.555$ and 0.121 respectively while the RMS errors were found to be $0.43 \mathrm{~cm}, 0.77 \mathrm{~cm}$ and $0.99 \mathrm{~cm}$.

The weak correlation between the NIGNET GNSS/GPS precipitable water vapour and the NCEP Reanalysis 2, as indicated by the values of $\mathrm{R}^{2}$ is not unrelated to the fact that the NIGNET GNSS/GPS network was not designed for atmospheric research. Hence, the meteorological parameters needed for the computation of the GNSS/GPS PWV were obtained from meteorological stations which are not collocated with the GNSS/GPS antennae (ULAG is about 10.17 $\mathrm{km}$ from the Murtala Muhammed International Airport, Lagos; OSGF is about $23.83 \mathrm{~km}$ from the Nnamdi Azikiwe International Airport, Abuja; and ABUZ is about $62.54 \mathrm{~km}$ from the Kaduna Airport, Kaduna) thereby introducing great error into the calculation. This is corroborated by Mengistu et al., who stated that the surface pressure of $1 \mathrm{hPa}$ can cause up to $0.35 \mathrm{~mm}$ error in GPS PWV. ${ }^{15}$

The spatial variation of PWV as modelled by NCEP Reanalysis 2 is shown in Figure 6 for four given days within the year 2012. The 16 January figure indicates that most of the entire country is dry as the tropical continental air mass (cT) blowing in from the Sahara Desert predominates at this time. By 15 April, the maritime tropical air mass (mT) is gradually becoming much stronger and it blows 
more moist air from the Atlantic Ocean over the southern part of the country, and by 16 August the entire country is covered by the moist $\mathrm{mT}$ and the country is now in the thick of the monsoon season. By 15 November, the $\mathrm{cT}$ has taken over again and $\mathrm{mT}$ has weakened considerably, hence marking the beginning of dry harmattan season.

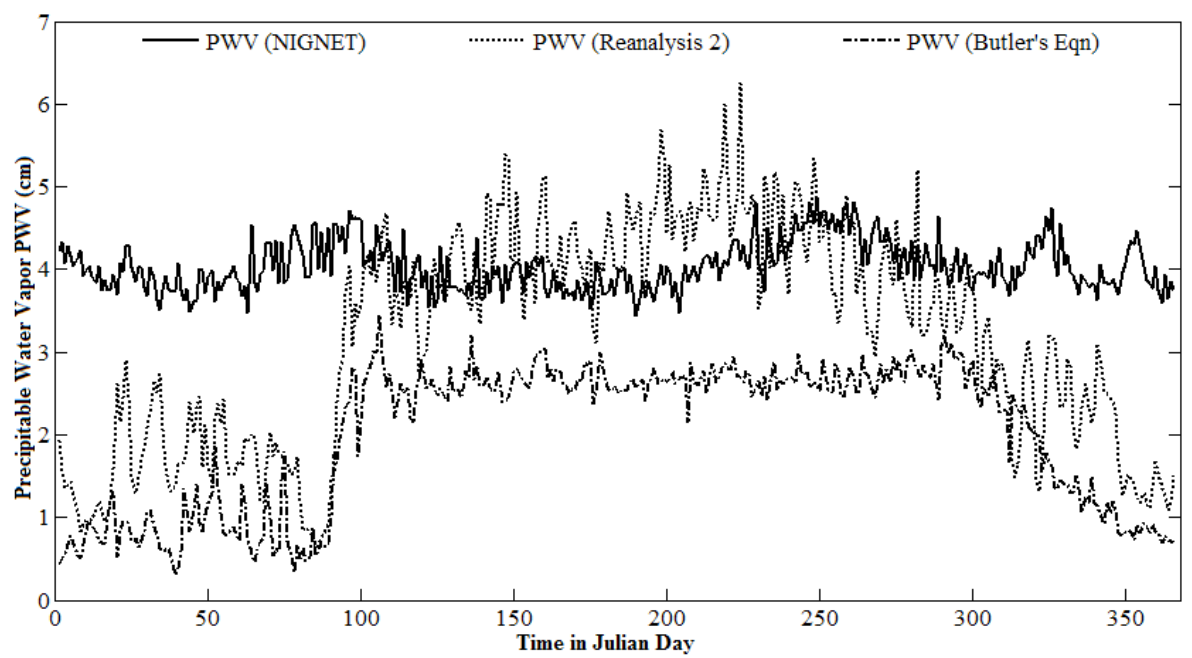

Figure 3: Time series plot of PWV from NIGNET GPS/GNSS, NCEP Reanalysis II and surface meteorological (Butler's equation) data for Zaria for year 2012.

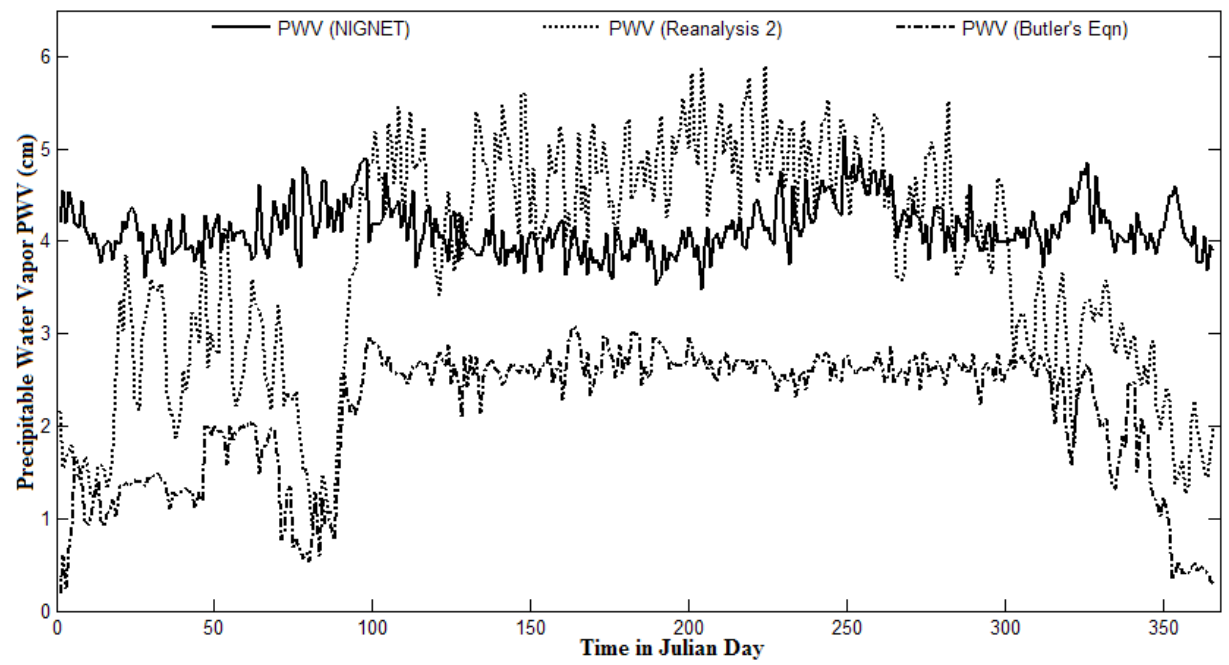

Figure 4: Time series plot of PWV from NIGNET GPS/GNSS, NCEP Reanalysis 2 and surface meteorological (Butler's equation) data for Abuja for year 2012. 


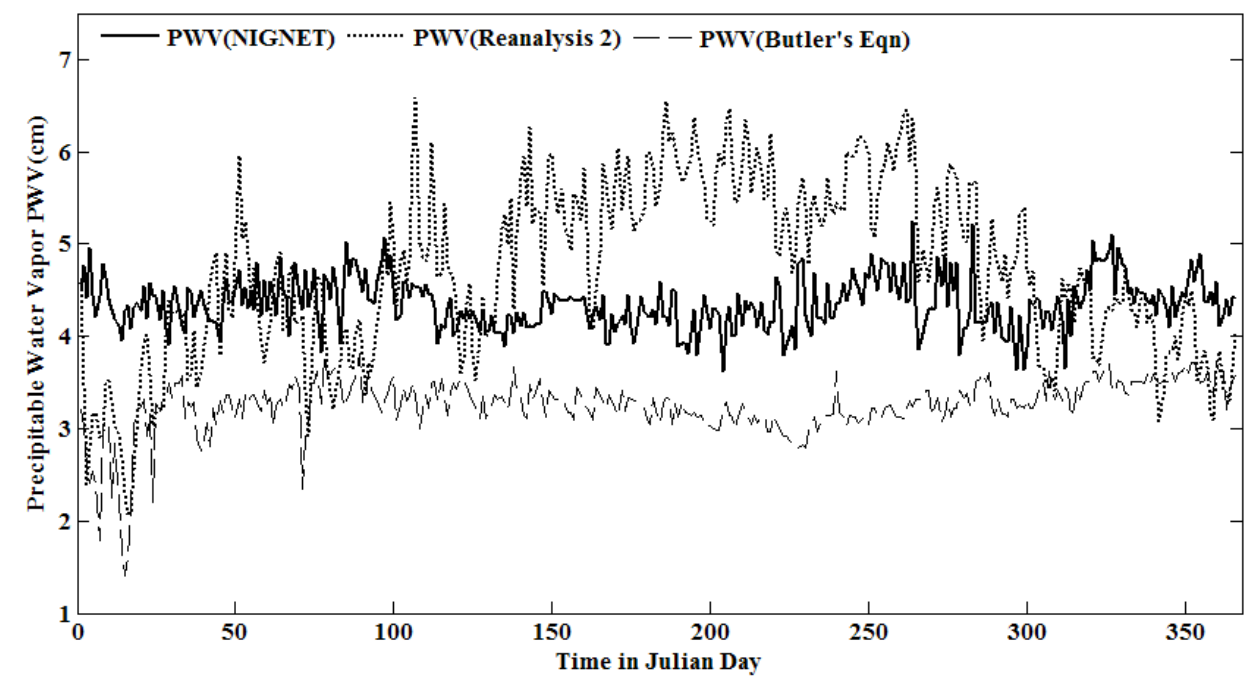

Figure 5: Time series plot of PWV from NIGNET GPS/GNSS, NCEP Reanalysis 2 and surface meteorological (Butler's equation) data for Lagos for year 2012.
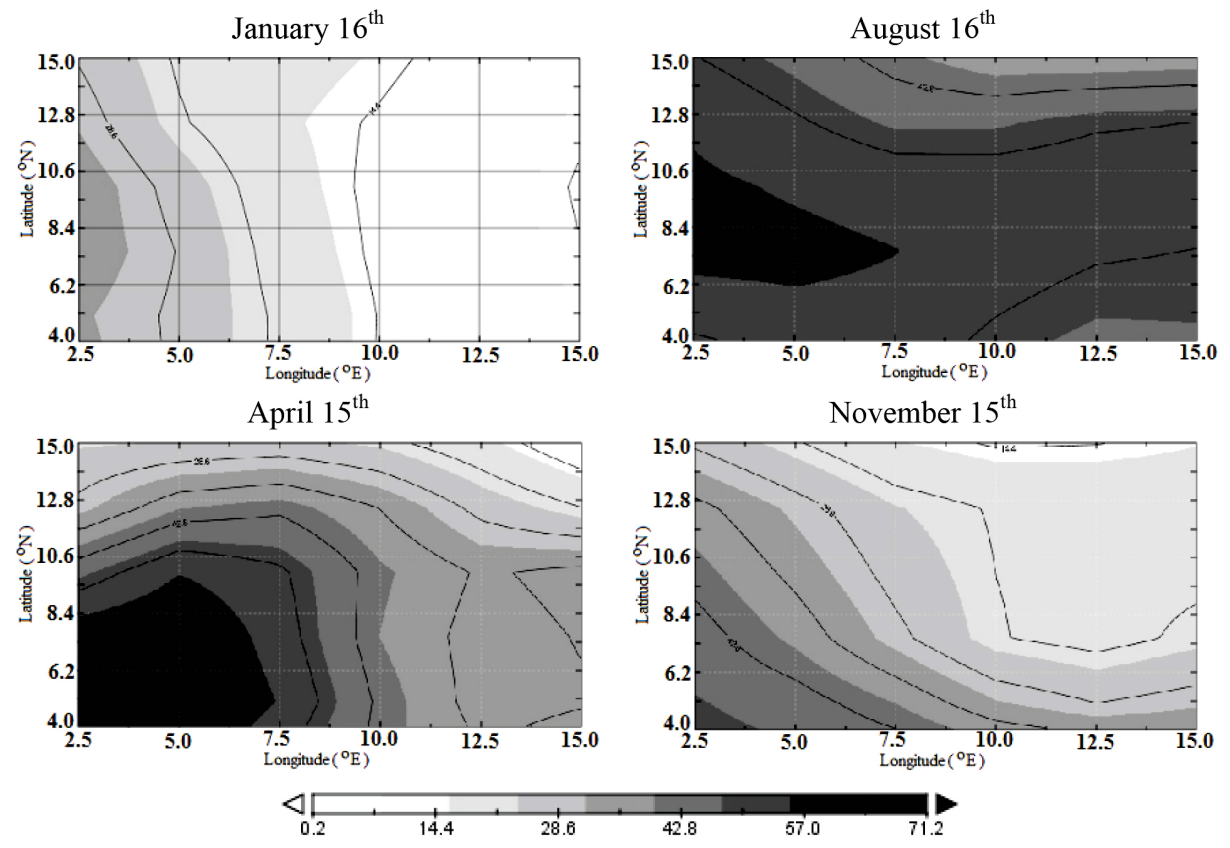

Daily Precipitable Water Vapor for Entire Atmosphere PWV(mm)

Figure 6: Spatial variation of PWV across Nigeria, generated with NCEP/DOE Reanalysis 2 data for year 2012. 


\section{CONCLUSION}

The PWV for the year 2012 had been estimated using combinations of GPS/GNSS data from the NIGNET network of antennae, the NCEP/DOE Reanalysis II data, and surface meteorological data (via the use of Butler's equation). It was observed that the GPS/GNSS PWV does not have good correlation with the NCEP/DOE Reanalysis II data, nor with the surface data PWV (see Table 2 for summary). This is in contrast to other researchers' results and the weak correlation could be explained from the fact that the NIGNET network of GPS/GNSS stations were not established to provide meteorological information that is vital in numerical weather prediction modelling, hence the lack of pressure and temperature sensors at the antenna sites. Considering the importance of PWV in weather prediction and climate studies, it is highly recommended by the authors that the government of Nigeria considers the upgrade of the NIGNET network to include pressure and temperature sensors, so that the GPS/GNSS network could be used for a realtime monitoring of PWV and also facilitate the use of GPS PWV as an important ingredient in numerical weather prediction data assimilation processes.

Table 2: Summary of the comparison between the GPS/GNSS PWV and NCEP Reanalysis 2 as well as Butler's equation.

\begin{tabular}{lllll}
\hline & \multicolumn{2}{l}{ NCEP Reanalysis 2 } & \multicolumn{2}{l}{ Butler's equation } \\
\cline { 2 - 5 } & $\mathrm{R}_{2}$ & RMS error $(\mathrm{cm})$ & $\mathrm{R}_{2}$ & RMS error $(\mathrm{cm})$ \\
\hline ABUZ (Zaria) & 0.080 & 0.32 & 0.114 & 0.34 \\
OSGF (Abuja) & 0.006 & 0.29 & 0.045 & 0.30 \\
ULAG (Lagos) & 0.105 & 0.99 & 0.004 & 0.28 \\
\hline
\end{tabular}

\section{ACKNOWLEDGEMENTS}

The authors wish to express their gratitude to the Nigerian GNSS network (NIGNET) for the GPS data used in this study. The authors also wish to express their gratitude to the reviewers for their suggestions and comments that has significantly improved the content of the paper. Much appreciation is extended to the Physical Science Division (PSD), Earth System, Research Laboratory (ESRL), Oceanic and Atmospheric Research (OAR), National Oceanic and Atmospheric Administration (NOAA), Boulder, Colorado, USA, for making the NCEP Reanalysis data available through their website (http://www.esrl.noaa.gov/psd/). 


\section{REFERENCES}

1. Vedel, H. \& Huang, X. Y. (2003). A NWP impact study with ground based GPS data. Paper for Danish Meteorological Institute, Copenhagen, Denmark.

2. Seco, A. et al. (2012). Rain pattern analysis and forecast model based on GPS estimated atmospheric water vapor content. Atmos. Environ., 49, 8593, https://doi.org/10.1016/j.atmosenv.2011.12.019.

3. Bevis, M. et al. (1992). GPS meteorology: Remote sensing of atmospheric water vapor using the global positioning system. J. Geophys. Res., 97, 15787-15801, https://doi.org/10.1029/92JD01517.

4. Butler, B. (1998). Precipitable water at KP - 1993-1998, MMA memo, no. 238, National Radio Astronomy Observatory, 30 November.

5. Businger, S. et al. (1996). The promise of GPS in atmospheric monitoring. Bull. Amer. Meteor. Soc., 77(1), 5-18, https://doi.org/10.1175/15200477(1996)077\%3C0005:TPOGIA\%3E2.0.CO;2.

6. Coster, A. J. et al. (1996). Measurements of precipitable water vapor by GPS, radiosondes, and a microwave water vapor radiometer. Proceedings of the 9th International Technical Meeting of the Satellite Division of The Institute of Navigation ION-GPS, Kansas City, Kansas, 17-20 September.

7. Behren, D. et al. (2000). An inter-comparison study to estimate zenith wet delays using VLBI, GPS and NWP models. Earth Planets Space, 52, 691-694, https://doi.org/10.1186/BF03352265.

8. Kwon, H.-T., Iwabuchi, T. \& Lim, G.-H. (2007). Comparison of precipitable water derived from ground-based GPS measurements with radiosonde observations over the Korean Peninsula. J. Meteorol. Soc. Jap., 85, 733746, https://doi.org/10.2151/jmsj.85.733.

9. Saastamoinen, J. (1972). Atmospheric correction for the troposphere and stratosphere in radio ranging of satellites. In Henriksen, W. et al. The use of artificial satellites for geodesy, geophysics monograph series, vol. 15. Washington DC: American Geophysical Union, 247, https://doi.org/10.1029/ GM015p0247.

10. Bevis, M., Businger, S. \& Chiswell, S. (1994). GPS meteorology: Mapping zenith wet delay onto precipitable water. J. Appl. Meteorol., 33, 379-386, https://doi.org/10.1175/1520-0450(1994)033\%3C0379:GMMZWD\%3E2.0 .CO;2.

11. Barde, J. et al. (2010). NIGNET - The new permanent GNSS network of Nigeria. Paper presented at the International Federation of Surveyors (FIG) Congress, 11-16 April, Sydney.

12. Kistler, R. et al. (2001). The NCEP-NCAR 50-year reanalysis: Monthly means CD-ROM and documentation. Bull. Am. Meteorol. Soc., 82, 247-267, https://doi.org/10.1175/1520-0477(2001)082<0247:TNNYRM>2.3.CO;2. 
13. Mlawer, E. J. (1997). RRTM, a validated correlated-k model for the longwave. J. Geophys. Res., 102, 16,663-16,682, https://doi.org/10.1029/97JD00237.

14. Prasad, A. K. \& Singh, R. P. (2009). Validation of MODIS Terra, AIRS, NCEP/DOE AMIP-II Reanalysis-2, and AERONET Sunphotometer derived integrated precipitable water vapor using ground-based GPS receivers over India. J. Geophys. Res., 114, DO5107, https://doi. org/10.1029/2008JD011230.

15. Mengistu, T. G., Blumenstock, T. \& Hase, F. (2015). Observations of precipitable water vapour over complex topography of Ethiopia from ground-based GPS, FTIR, radiosonde and ERA-Interim reanalysis. Atmos. Meas. Tech., 8, 3277-3295, https://doi.org/10.5194/amt-8-3277-2015. 